\title{
Preliminary Study Application on "Participatory" Teaching Mode in Pharmaceutical Organic Chemistry Experiment
}

\author{
Jianbo ZHOU, Xiaoying CUI, Chao XU, Ming ZENG, Wen CHEN* \\ Department of Basic Medicine, Changsha Medical University, Hunan, Changsha 410219, China \\ *Corresponding Author: chenwen0520@qq.com
}

\begin{abstract}
Keywords: Participatory teaching mode, Organic chemistry experiment, Pharmacy, Self-learning ability
\end{abstract}

\begin{abstract}
This paper introduces the concept and characteristics of "participatory Teaching Mode" which emphatically introduces participation teaching program carried out in the pharmaceutical professional organic chemistry experiment based on the example of "preparation of acetyl salicylic acid". It illustrates concrete steps and processes of participatory teaching mode and tasks undertaken and role played by the students and teachers. Student's self-learning ability and creative ability has been greatly improved through the "participatory" teaching model.
\end{abstract}

\section{Introduction}

Organic chemistry is a most important professional basic-course of pharmacy, and medicine major in the college, which directly impacts on the subsequent course like physical chemistry, instrumental analysis, drug synthesis, pharmaceutical analysis and other professional courses if student failed in this course. Organic chemistry experiment is also an important part of organic chemistry, including the basic experimental operation, organic synthesis, purification, identification and so on. It aims to enable students to develop the scientific attitude of seeking truth from facts, strengthen further consolidation and understanding of knowledge learned in the theoretical courses, train student's ability on operation, problems-seeking, problem-solving skills and innovation capability. While current organic chemistry experiment class mode adopted in our school is the traditional mode which belongs to "chalk and talk" and "spoon-feeding" teaching mode. The teacher firstly explains the purpose of the experiment, the experimental principle and the experimental procedure, and then the students start to operate accordingly with the lack of lack of initiative sense of participation and opportunities to think independently, problem-seeking and problem-solving. This mode to cultivate the students lack independence, initiative and creativity. Students cultivated in this mode will be lack of independence, initiative and innovation ability. How to improve students independence, initiative and innovation ability during the experiment is one of the issues we've been exploring and research, as well as one of the problems that we have to face and solve in organic chemistry experiment teaching reform. In order to solve this problem, we have introduced "participatory" teaching mode to the pharmacy organic chemistry experiment teaching in our school in 2014, attempting to build a new teaching model, teaching contents and evaluation system to train students to practice the spirit of seeking truth from facts and improve students' self-learning ability and creative ability.

\section{Participatory teaching mode feature}

"Participatory" ${ }^{[1]}$ teaching mode is carried out by teacher's purposeful and positive guidance, and students will participate in teaching activities initiatively which includes preparation of teaching activities, specific implementation of teaching activities, teaching effect, feedback and so on. By the enthusiasm of the teacher's 'guide' and student's active "participation", we can increase student's 'interest in learning, improve their problem-seeking, problem-analysis and problem-solving ability, and develop student's innovation ability and spirit of collaboration. Between teachers and students, we could also establish an equal, harmonious and democratic relationship. Its main features are listed as following: 


\section{A. "Double-hosts" ${ }^{[2]}$}

"Participatory" teaching mode adopts the advantage of behaviorism theory and building socialist theory. The teacher is host of the design process, "subject", while student is the host of learning which forms "double-hosts" during the entire teaching process. Teacher's role is no longer a simple transfer knowledge, but to guide students to actively construct and continue to improve knowledge system.

\section{B. Participation during the entire process ${ }^{[3]}$}

"Participatory" teaching mode requires teachers to guide students during the entire process, is by no means leaving the class for student to develop by their own with indifference. Students will participate in the entire process and the whole teaching process, including the development of teaching objectives, design teaching programs, creating teaching atmosphere, prepare teaching materials, teaching monitoring, evaluation, feedback and so on. It's not allowed to play procedurally and casually with a show only in certain sectors.

\section{Unpredictability ${ }^{[4]}$}

In traditional teaching mode, teacher firstly designs teaching objectives and content, and what the student should do is only to accept passively. Teaching targets, teaching process, teaching results are open in "participatory" teaching mode and it is difficult to predict the specific circumstances in advance. Therefore, teachers should monitor the entire process, provide guidance, and point out and make the appropriate changes for unreasonable experimental scheme and operation.

\section{Diversity ${ }^{[5]}$}

"Participatory" teaching is a teaching mode which requires a variety of teaching methods to operate smoothly, such as: group discussions, demonstrations and exercises guidance, case studies, multimedia, audio, or video activities and so on.

\section{E.Interaction ${ }^{[6]}$}

Traditional teaching is teacher-centered with focuses on environmental education and a decisive influence on the development of students with absolutely dominant place during educational process and the fact that student is the object of education, rather than the main body of education. Communication between teacher and student is relatively few and student always thinks the teacher is the superior and is afraid to exchange their ideas and practice, and teacher-student relationship is not built on the basis of equality and democracy. "Participatory" teaching mode creates a "double-hosts" during the whole teaching process and enable student to explain their ideas and opinions to teacher and teacher will get further understanding of their students based on the communication, and give a reasonable evaluation and guidance of the student. Moreover, student should mutual exchange, learn from each other and improve each other.

\section{"Participatory" teaching mode in our school}

In order to implement the "participatory" teaching mode in organic chemistry experiment teaching of Pharmacy, we firstly determine the appropriate experimental project and we divide experimental teaching into course experimental teaching project and open experiment teaching program according to the sources of the experiment project. The course experimental teaching project is the one student has to do in the class, while open experiment teaching project is the one student can choose according to interest and hobby, main from student's innovative subject and teacher's subject. According to operational depth and difficulty of the course, we also divide the experimental project into basic experiment, comprehensive experiment and designed experiment. Each experimental 
project consists of the experiment preparation phase, the implementation phase and feedback phase. The experiment preparation phase includes experimental teaching objective design, experimental teaching program design and so on. Experiment feedback phase includes review, summary and examination of experiment teaching. Teachers should guide students at all stages of the experiment to fully mobilize their "subjectivity", enable students to give full play to their initiative and the completion of the experiment project. The specific implementation details are as follows:

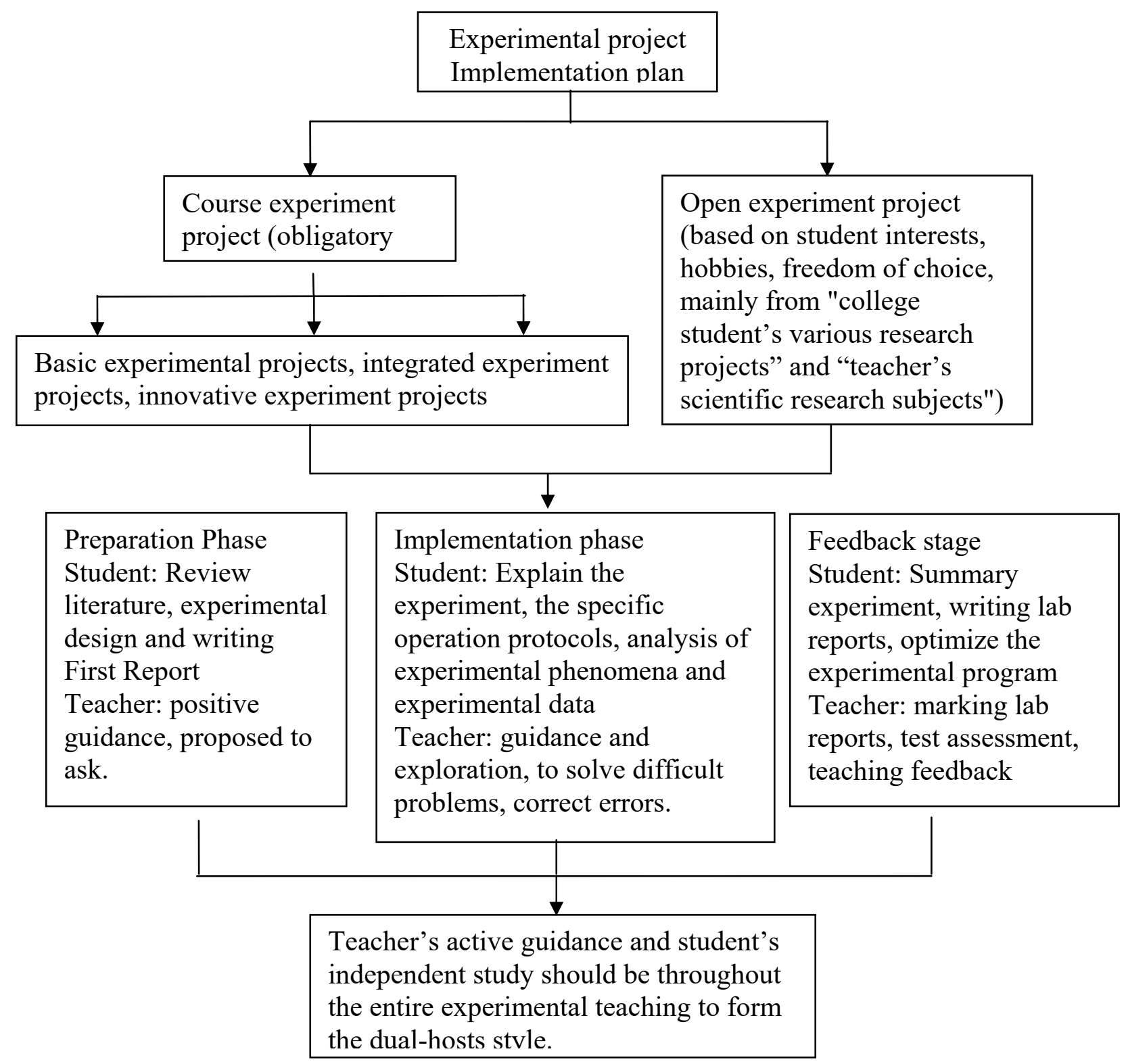

Fig. 1 The specific implementation

\section{Pharmacy organic chemistry "participatory" teaching mode example}

Author takes the example "preparation of acetyl salicylic acid" to make an illustration of specific circumstances in "participatory" teaching mode carried out in our college organic chemistry experiment. The specific steps are as follows: 


\section{A.Preparatory phase}

We group the students from Pharmacy 2014 Class 1 into four small classes with 16-17 students per class. Each teacher is responsible for a small class, and each class is also divided into 4 small teams marked red, orange, green, blue. Each team selects captain and starts to arrange the experiment project.

Students use spare time to review the books, periodicals, or network to understand the application of acetylsalicylic acid in medicine industry, the principle of preparation, production method and purification of product with preview report at first. The captain should organize discussion on experiment scheme, determination of the experiment scheme and sends the experiment reported to the laboratory assistant teacher in advance.

\section{B. Experimental Implementation Phase}

Each group should dispatch 1-2 students to explain the purpose of the experiment, the experimental principle, experimental concrete steps and precautions in class; the other two students supplement. Students should timely consult with other students and teachers on the part that they feel confused. Teacher should promptly pointed out the unreasonable experimental scheme and require students to timely adjust the experimental program. In this class, we have come up with two kinds of practical experimental scheme and one impractical scheme: (1) salicylic acid and acetic anhydride produce acetylsalicylic acid by the reaction. In this scenario, student made two sets of reaction apparatus, as shown in Figure a, b. On this reaction, student also proposed two kinds of catalysts, concentrated phosphoric acid and concentrated sulfuric acid; (2) salicylic acid and acetic anhydride produce acetylsalicylic acid by the reaction. The equipment was shown in figure c. In this case, we can also use concentrated phosphoric acid and concentrated sulfuric acid. And in the purification stages of product, students generally mentioned the recrystallization method, but can use different solvents such as: ethanol and water, ethyl acetate, petroleum and so on. When we test product purity, the students had mentioned different methods like determination of melting point, infrared spectroscopy and salicylic acid color reaction with $\mathrm{FeCl} 3$.
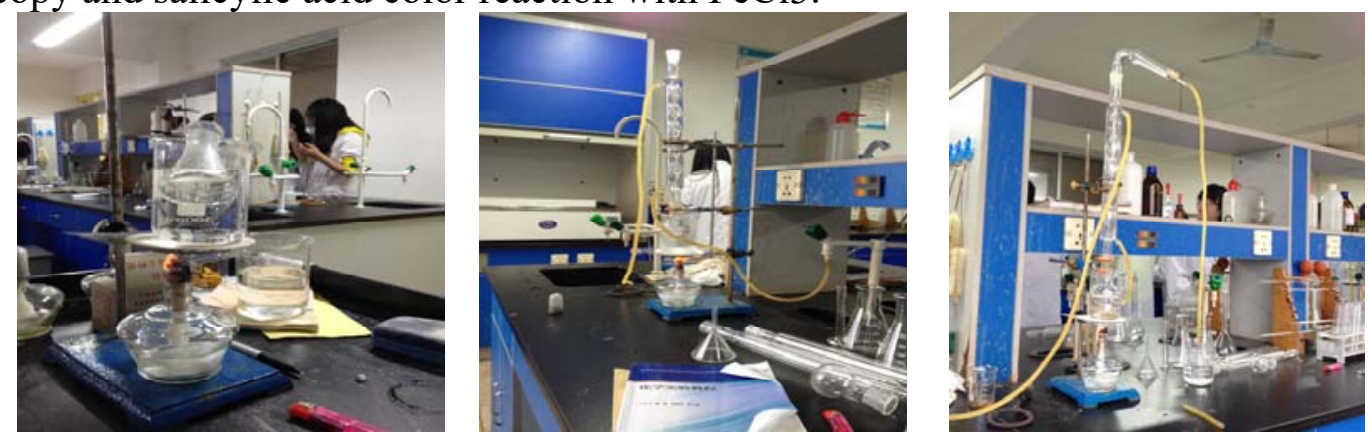

Fig. 2 Experimental Implementation

Students start to operate after explain and discussion in groups. During the experiment, teachers continue to inspect the operation of the students, and will point out the error timely, but also to constantly remind students to observe experimental phenomena and data recording.

\section{Experimental feedback phase}

After the experiment, student should be promptly write lab reports and make a reasonable explanation on the some phenomena and experimental data. At the same time, teacher should timely report correct the reports. Teacher should make reasonable adjustments on "participatory" teaching mode according to teaching state of the whole experiment. 


\section{Conclusion}

In short, student's learning enthusiasm, self-learning, problem-analysis, problem-solving and innovation ability have been greatly improved since we carried out "participatory" teaching mode in 2014 Pharmaceutical organic chemistry experiment classes. But we are also facing some problems in our education reform as below: (1) "participatory" teaching mode is more suitable for small classes, which requires more financial, material and human support. (2) "participatory" teaching mode requires more classes than that of traditional teaching mode. (3) "participatory" teaching mode requires teachers to update teaching concept, teachers teaching level and professional level. These issues that we face now require us to solve in future promotion of "participatory" teaching mode.

\section{Acknowledgements}

Fund Projects: Natural Science Funded by Education Department of Hunan Province (No:13C1127).

\section{References}

[1] Schultz K. Rethinking Classroom Participation: Listening To Silent Voices. New York: Teachers College Press, 2009

[2] Guangbing Zhang. Participatory Instructional Design Research [D] Sichuan: Southwest University Thesis, 2009

[3] Xiaoting Chen. Science And Technology Innovation Herald 2015 (23): 167-168

[4] Shan Shen, Youjian Wang, Hua Guan. Laboratory Research and Exploration 2014 (33): 149-152

[5] Hongshen Liu, Qianyu Wang. Career Horizon, 2014 (4): 61-63

[6] Haiying Li. Educational Theory and Practice, 2002, (9): 43-47 